\title{
Severe thrombocytopenia in a patient with inosine triphosphatase (ITPA)-CC genotype caused by pegylated interferon (IFN)-a-2a with ribavirin therapy: a case report
}

Weimin Jiang ${ }^{1,2}$, Hisashi Hidaka ${ }^{2 *}$, Takahide Nakazawa ${ }^{2}$, Hiroyuki Kitagawa ${ }^{2}$ and Wasaburo Koizumi²

\begin{abstract}
Background: Pegylated interferon combined with ribavirin treatment is an effective therapy for chronic hepatitis $C$ viral infection. However, pegylated interferon combined with ribavirin is associated with various adverse reactions. Severe thrombocytopenia is a life-threatening side effect of interferon therapy that can lead to bleeding. It is generally understood that the inosine triphosphatase-CC genotype does not have a significantly lower reduction by pegylated interferon combined with ribavirin in the mean platelet counts compared with the AA/CA genotype. We report a case of severe thrombocytopenia that developed in a patient with chronic hepatitis $C$ treated with pegylated interferon combined with ribavirin in spite of having the inosine triphosphatase-CC genotype.
\end{abstract}

Case presentation: A 57-year-old female had been diagnosed as having HCV infection in 2008. The inosine triphosphatase gene showed one single nucleotide polymorphism (rs 1127354) C/C (major homozygous) and the IL28B gene showed single nucleotide polymorphism (rs8099917 T/T, rs 1881222 T/T) (major homozygous). The patient was treated with pegylated interferon $180 \mu \mathrm{g}$ once a week combined with ribavirin $600 \mathrm{mg}$ per day from April 2011. The hepatitis $\mathrm{c}$ virus ribonucleic acid turned negative 9 weeks after treatment with pegylated interferon combined with ribavirin. During the therapy, the platelet count remained above $8.0 \times 10^{4} / \mu \mathrm{l}$ for about 9 months. In January 2012, the platelet count was $6.8 \times 10^{4} / \mu \mathrm{l}$. In February 2012, the 44th week from the beginning of the treatment, a sudden decrease in the platelet count to $0.8 \times 10^{4} / \mu$ was observed. After prednisolone was administered, the platelet count increased. Finally the platelet count had risen above normal range.

Conclusion: We should pay careful attention in the differential diagnosis for patients with the inosine triphosphatase-CC genotype because, although rare, severe thrombocytopenia could occur.

Keywords: Hepatitis C, ITPA, Pegylated interferon, Thrombocytopenia

\section{Background}

Chronic infection with hepatitis $\mathrm{C}$ virus $(\mathrm{HCV})$ affects up to 170 million individuals worldwide [1] and may lead to progressive hepatic fibrosis and cirrhosis, with risk of liver failure and hepatocellular carcinoma. Pegylated interferon (PEG-IFN) combined with ribavirin (RBV) treatment (PEG-IFN/RBV) is an effective therapy for chronic $\mathrm{HCV}$ infection. However, PEG-IFN/RBV is

\footnotetext{
* Correspondence: hisashi7@kitasato-u.ac.jp

${ }^{2}$ Department of Gastroenterology, Kitasato University School of Medicine, East Hospital, 2-1-1 Asamizodai, Minami-ku, Sagamihara, Kanagawa 252-0380, Japan

Full list of author information is available at the end of the article
}

associated with various adverse reactions. Some of these side effects are mild, such as flu-like symptoms. Some others can be very severe and even lead to lethal consequences [2]. Severe thrombocytopenia is a life-threatening side effect of interferon therapy that can lead to bleeding, and even death, if diagnosis and treatment are not adequately given. Therefore, how to identify the possibility of thrombocytopenia early is critical for patients treated with PEG-IFN/RBV.

Recently, genome-wide association studies have identified that the genetic variant of rs1127354 single nucleotide polymorphisms (SNPs) in the inosine triphosphatase

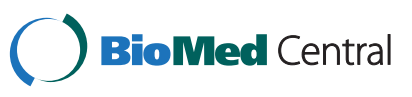


(ITPA) gene, which encodes a protein that hydrolyses inosine triphosphate (ITP), has been found to be associated with thrombocytopenia. The ITPA-AA/CA genotype was independently associated with a higher degree of reduction in platelet counts at 4 weeks as well as protection against the reduction of hemoglobin in patients treated with PEGIFN/RBV [3-5], while the CC genotype had significantly lower reduction in the mean platelet counts compared with the $A A / C A$ genotype [5]. Here, we report a case of severe thrombocytopenia that developed in a patient with chronic hepatitis $C$ treated with PEG-IFN- $\alpha 2$ a plus ribavirin in spite of having the ITPA-CC genotype.

\section{Case presentation}

A 57-year-old female had been diagnosed as having HCV infection in 2008 in another hospital. Laboratory test showed that her serum and anti-HCV, and HCV ribonucleic acid (RNA) were positive in October 2010 at Kitasato University East Hospital. The patient's laboratory findings prior to receiving treatment, in March 2011, are shown in the Table 1. The ITPA gene showed one single nucleotide polymorphism (SNP) (rs1127354) $C / C$ (major homozygous) and the IL28B gene showed SNP (rs8099917 T/T, rs11881222 T/T) (major homozygous) [5].

She had a history of a little alcohol consumption and of smoking 20 cigarettes per day for longer than 30 years. Her height was $156.3 \mathrm{~cm}$, and her body weight was $57.5 \mathrm{~kg}$. Her mother had a history of hypertension. The patient had no history of ever having a blood transfusion. The ultrasonographic examination showed that the patient's liver, spleen, and pancreas were normal, but she

\begin{tabular}{|c|c|c|c|c|c|}
\hline WBC & 5800 & $/ \mu \mathrm{L}$ & CRP & $<0.10$ & $\mathrm{mg} / \mathrm{dl}$ \\
\hline $\mathrm{RBC}$ & $404 \times 10^{4}$ & $/ \mu \mathrm{L}$ & $\mathrm{LDH}$ & 238 & $U / L$ \\
\hline $\mathrm{Hb}$ & 13.5 & $\mathrm{~g} / \mathrm{dL}$ & UA & 5.8 & $\mathrm{mg} / \mathrm{dL}$ \\
\hline Plt & $16.7 \times 10^{4}$ & $/ \mu \mathrm{L}$ & BUN & 12.6 & $\mathrm{mg} / \mathrm{dL}$ \\
\hline PT & 11.7 & $\mathrm{sec}$ & $\mathrm{Cr}$ & 0.52 & $\mathrm{mg} / \mathrm{dL}$ \\
\hline AST & 41 & $\mathrm{IU} / \mathrm{L}$ & $\mathrm{Na}$ & 141 & $\mathrm{mEq} / \mathrm{l}$ \\
\hline ALT & 46 & IU/L & K & 3.8 & mEq/l - \\
\hline TP & 7.6 & $\mathrm{~g} / \mathrm{dL}$ & $\mathrm{HBsAg}$ & $(-)$ & - \\
\hline Alb & 4.4 & $\mathrm{~g} / \mathrm{dL}$ & HCVAb & $(+)$ & - \\
\hline TBIL & 0.5 & $\mathrm{mg} / \mathrm{dL}$ & HCV-RNA & 6.3 & $\log \mid \mathrm{U} / \mathrm{m}$ \\
\hline ALP & 248 & $\mathrm{IU} / \mathrm{L}$ & Genotype & $1 \mathrm{~B}$ & \\
\hline$\gamma$-GTP & 20 & IU/L & & & \\
\hline
\end{tabular}

WBC, white blood cells; RBC, red blood cells; Plt, platelets; PT, prothrombin time; AST, aspartate aminotransferase; ALT, alanine aminotransferase; TP, total protein; Alb, albumin; TBIL, total bilirubin; ALP, alkaline phosphatase; $\gamma-G T P$, gamma glutamyl transpeptidase; CRP, C-reactive protein; $L D H$, lactate dehydrogenase; UA, uric acid; BUN, blood urea nitrogen; $\mathrm{Cr}$, creatinine; $\mathrm{Na}$, natrium; $\mathrm{K}$, potasium; $\mathrm{HBsAg}$, hepatitis $B$ surface antigen; $\mathrm{HCV}$, hepatitis $\mathrm{C}$ virus antibody; HCV-RNA, hepatitis $C$ virus ribonucleic acid. had gallstones. The liver biopsy revealed chronic active hepatitis (fibrosis grade 3 and inflammatory activity grade 1) in the Metavir classification and a hepatic activity index score of 1-1-3-3 (Figure 1).

The patient was treated with PEG-IFN- $\alpha-2 \mathrm{a} 180 \mu \mathrm{g}$ once a week combined with ribavirin $600 \mathrm{mg}$ per day from April 2011. The HCV RNA turned negative 9 weeks after treatment with PEG-IFN- $\alpha-2 \mathrm{a}$. During the therapy, the platelet count remained above $8.0 \times 10^{4} / \mu$ l for about 9 months. In January 2012, the platelet count was $6.8 \times$ $10^{4} / \mu \mathrm{l}$. In February 2012, the 44th week from the beginning of the treatment, a sudden decrease in the platelet count to $0.8 \times 10^{4} / \mu \mathrm{l}$ was observed (Figure 2). Severe thrombocytopenia caused by the PEG-IFN- $\alpha-2 a$ therapy was suspected. Therefore, the PEG-IFN- $\alpha-2 a$ and ribavirin were discontinued. The patient was then admitted to our hospital.

On admission, the blood pressure, temperature and pulse of the patient were normal. Her white blood cell and neutrophil values were also in the normal range. And there was no evidence of bacterial, viral, or other microorganism infection. Purpura were noted on both lower limbs and her trunk. The white blood cell count was $3000 / \mu \mathrm{l}$, the red blood cell count was $3.14 \times 10^{6} / \mu \mathrm{l}$, hemoglobin was $11.2 \mathrm{~g} / \mathrm{dl}$, but the platelet count had decreased to $1.1 \times 10^{4} / \mu \mathrm{l}$. The liver function and coagulation function were normal. But the PAIgG was elevated to $180 \mathrm{ng} / \mathrm{L}$ (normal range, 9-25 $\mathrm{ng} / \mathrm{L}$ ).

A bone marrow aspiration examination was performed to investigate the etiology of the thrombocytopenia. The specimen revealed that there was hypoplasia of myelocytes (especially in megakaryocytes) but no myeloblasts, which did not suggest any evidence of bone marrow disease (Figure 3).

Based on these results, she was diagnosed as having immune-mediated thrombocytopenia caused by the PEGIFN- $\alpha-2 a$ therapy. Therefore, the PEG-IFN/RBV was discontinued, but the platelet count remained below $1.0 \times 10^{4}$ / $\mu \mathrm{l}$. We confirmed that her anti-Helicobacter pylori was positive but did not perform eradication therapy. In March 2012, $60 \mathrm{mg}$ of prednisolone were administered orally. After starting corticosteroid therapy, the platelet count increased gradually. Then the prednisolone was gradually tapered down by $10 \mathrm{mg}$ every 4 days, the platelet count gradually rose above $10 \times 10^{4} / \mu \mathrm{l}$, and the PAIgG was decreased to $80 \mathrm{ng} / \mathrm{L}$. When the prednisolone dosage decreased to $30 \mathrm{mg}$ per day orally, she was discharged. The prednisolone was gradually tapered off, and the platelet count returned to normal (Figure 2). Prednisolone was discontinued in May 2012. Her platelet count remained normal during the follow-up. And HCV RNA has never been detected since. She was diagnosed as having a sustained virologic response (SVR) 6 months later. 
(A)

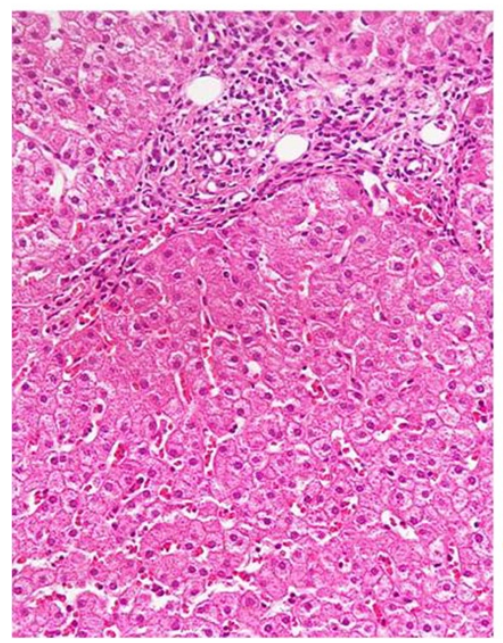

(B)

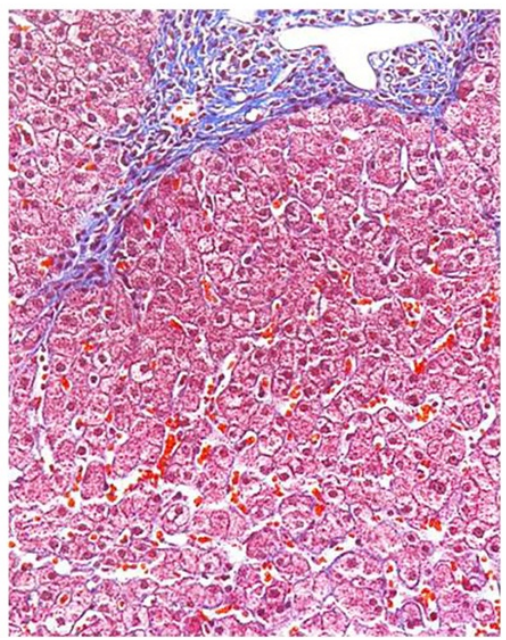

Figure 1 Liver biopsy (A: Hematoxylin and Eosin stain $\times 100$; B: Masson trichrome stain $\times 100$ ): fibrosis grade 3 and inflammatory activity grade 1 in the Metavir classification, Histologic activity index score: 1-1-3-3.

\section{Discussion}

To our knowledge, this is the first case report to assess the relationship between severe thrombocytopenia that developed in a patient treated with PEG-IFN/RBV and that patient having the ITPA genotype. It is a worthwhile case because, in spite of having the ITPA-CC genotype, the patient developed severe thrombocytopenia caused by the PEG-IFN/RBV treatment.

It is generally thought that an ITPA genetic variant is independently associated with reduction in the mean platelet counts for weeks $2,4,8$, and 12 [5]; while it is also associated with the reduction of hemoglobin for those same weeks caused by the RBV [5]. On the other hand, $I L 28 B$ genetic variant strongly associated with the response to PEG-IFN/RBV [6]. Patients with the IL28$T T$ genotype exhibit higher prevalence of virologic response compared to those with IL28B-TC/CC [6]. When we began to administer the PEG-IFN/RBV treatment, we

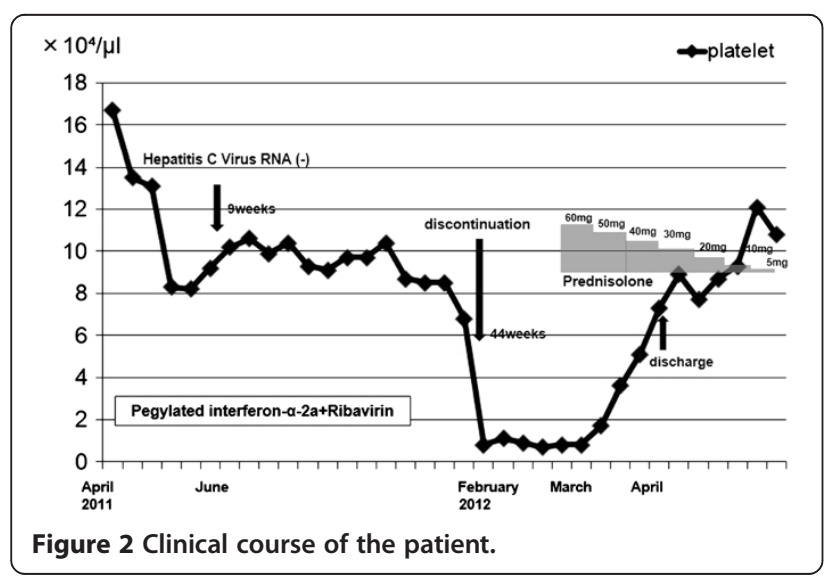

expected the possibility of SVR and had been cautious of the reduction of hemoglobin because the patient had the $I L 28 B-T T$ and ITPA-CC genotypes. Indeed, she achieved negative HCV RNA after only 9 weeks administration of PEG-IFN/RBV and her hemoglobin level had gradually decreased to a maximum of $9.6 \mathrm{~g} / \mathrm{dl}$. The side effects of PEG-IFN/RBV treatment are widely known, such as leukopenia, anemia, and thrombocytopenia. Hematologic abnormalities often lead to dose reduction and premature withdrawal from therapy in $10 \%-14 \%$ of patients [7]. It is not rare that mild-to-moderate thrombocytopenia is caused by PEG-IFN/RBV, and it has been attributed to a direct inhibition of stem cell proliferation and differentiation in the bone marrow [8]. Yamane et al. reported IFN- $\alpha$ directly inhibited cytoplasmic maturation and platelet production

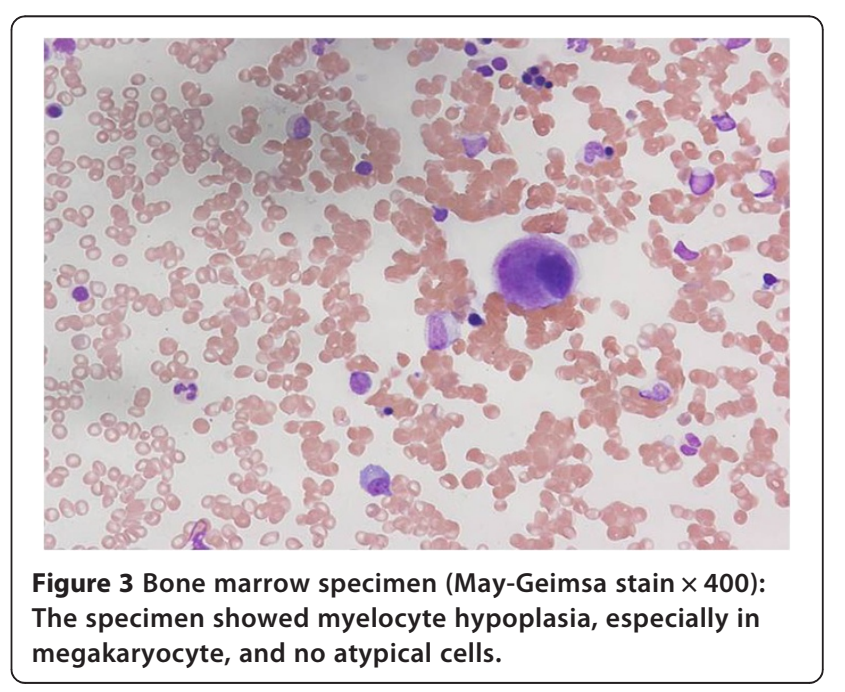


but not proliferation or endomitosis in human primary megakaryocytes [9]. However, severe thrombocytopenia (platelet counts less than $2.5 \times 10^{4} / \mathrm{mm}^{3}$ ) during interferon therapy is rare, and it is a life-threatening side effect.

In the present case, in the early period of administration (within 12 weeks) of PEG-IFN/RBV, mild-tomoderate thrombocytopenia was caused by the treatment, but the platelet count remained at or around $10 \times 10^{4} / \mu \mathrm{l}$ for 9 months. Li et al. reported in their review of severe thrombocytopenia induced by IFN- $\alpha$ in 17 patients [10] that the median onset time from the administration of IFN- $\alpha /$ PEG-IFN- $\alpha$ treatment was 3.6 months (range, $1-36$ months), and the patients could recover by discontinuing the IFN- $\alpha /$ PEG-IFN- $\alpha$ and administering an immunosuppressant. It is noteworthy that they reported that 16 patients $(94 \%)$ had reached SVR in spite of a short period of IFN- $\alpha$ administration. Generally, PEG-IFN/RBV can achieve rates of an SVR of less than $50 \%$ in patients with $H C V$ genotype 1 [2]. Therefore, there might be a correlation between severe thrombocytopenia and SVR that is caused by PEG-IFN/RBV therapy.

It is necessary to consider the mechanism in the present case of this severe thrombocytopenia. The IFN- $\alpha$ treatment is considered an immune-modulator and increases the risk for immune thrombocytopenia purpura in patients with hepatitis $C$ [10], but the mechanism of IFN-induced autoimmune thrombocytopenia is unclear [10]. IFN- $\alpha /$ PEGIFN- $\alpha$ can induce the production of autoantibody against thrombocytes, such as platelet antibody, which can lead to immune-mediated thrombocytopenia [11]. This situation is critical and may sometimes result in death. IFN can enhance the expression of major histocompatibility class I antigens and promote the production of IL-1 (interleukin 1) and TNF- $\alpha$ (tumor necrosis factor alpha). The over expression of these cytokines can induce autoimmune disease [12]. It is observed that higher Th1 (T helper 1) cell reactivity with platelets is related to idiopathic thrombocytopenic purpura (ITP) patients. PEG-IFN can increases IFN- $\gamma$ secretion and improve CD4 T cell response in $\mathrm{HCV}$-infected patients [13]. This may be one of the reasons of autoimmune thrombocytopenia during PEG-IFN treatment [14]. Recently, it is considered that autoimmune thrombocytopenia is associated with imbalance of Treg/ Th17 cells [15]. But, to our knowledge, there are no data in PEG-IFN induced thrombocytopenia.

Regarding the treatment, we discontinued PEG-IFN/ RBV after we diagnosed IFN-induced autoimmune thrombocytopenia and administrated $60 \mathrm{mg}$ of prednisolone first. Li et al. reported that early administration of immunosuppressant was an effective therapy for IFN- $\alpha$ induced severe thrombocytopenia [10].

Finally, it was considered that this case was "possible" drug-induced immune thrombocytopenia based on criteria and level of evidence for establishing a causative relationship in drug-induced thrombocytopenic purpura by George et al. [16,17]. It is the reason that this case meets only their first criteria and evidence: therapy with the candidate drug preceded the thrombocytopenia, and recovery from thrombocytopenia was complete and sustained after discontinuation of therapy.

The 2011 practice guideline by the AASLD (American Association for the Study of Liver Diseases) recommended that $I L 28 B$ genotype variants are robust pretreatment predicators of the SVR to PEG-IFN/RBV in patients with genotype 1 chronic $\mathrm{HCV}$ infection [1]. In thrombocytopenia caused by PEG-IFN/RBV, there is a tendency that patients with the ITPA-CC genotype are considered to be less at risk than those with the ITPA-CA/AA genotype. However, the newest treatment (PEG-IFN/RBV and protease inhibitors) might weaken this tendency. Therefore, this case of severe thrombocytopenia that developed in a patient with chronic hepatitis C treated with PEG-IFN/RBV in spite of the patient having the ITPA-CC genotype should be kept in mind.

\section{Conclusion}

In conclusion, it is generally understood that the $C C$ genotype had significantly less reduction in the mean platelet counts compared with the $A A / C A$ genotype. However, we should pay careful attention in the differential diagnosis for patients with the ITPA-CC genotype because, although rare, severe thrombocytopenia could occur.

\section{Consent}

Written informed consent was obtained from the patient for publication of this Case Report and any accompanying images. A copy of the written consent is available for review by the Editor-in-Chief of this journal.

\section{Competing interest}

The authors declare that they have no competing interests.

\section{Authors' contributions}

WJ and $\mathrm{HH}$ gathered the information for this case and were the major contributors in writing the manuscript. TN contributed to the writing in the discussion section and the genome sequence techniques. HK and WK contributed to the writing in the discussion section. All authors read and approved the final version of the manuscript.

\section{Acknowledgements}

We thank Atsuko Takeuchi and Akitaka Shibuya of Kitasato University School of Medicine for their assistance of genome sequence techniques. We also thank Professor Yasuhito Tanaka, Department of Virology and Liver Unit, Nagoya City University Graduate School of Medical Sciences and Robert E. Brandt (Founder, CEO, and CME, of MedEd Japan) for editing the manuscript.

\section{Author details}

'Department of Infectious Disease, Huashan Hospital, Fudan University, Shanghai, China. ${ }^{2}$ Department of Gastroenterology, Kitasato University School of Medicine, East Hospital, 2-1-1 Asamizodai, Minami-ku, Sagamihara, Kanagawa 252-0380, Japan.

Received: 28 August 2013 Accepted: 10 March 2014 Published: 12 March 2014 


\section{References}

1. Ghany MG, Nelson DR, Strader DB, Thomas DL, Seeff LB, American Association for Study of Liver Diseases: An update on treatment of genotype 1 chronic hepatitis $C$ virus infection: 2011 practice guideline by the American Association for the Study of Liver Diseases. Hepatology 2011, 54:1433-1444.

2. Hoofnagle $J H$, Seeff $L B$ : Peginterferon and ribavirin for chronic hepatitis $C$. N Engl J Med 2006, 355:2444-2451.

3. Fellay J, Thompson A, Ge D, Gumbs CE, Urban TJ, Shianna KV, Little LD, Qiu P, Bertelsen AH, Watson M, Warner A, Muir AJ, Brass C, Albrecht J, Sulkowski M, McHutchison JG, Goldstein DB: ITPA gene variants protect against anemia in patients treated for chronic hepatitis C. Nature 2010, 464:405-408.

4. Thompson AJ, Fellay J, Patel K, Tillmann HL, Naggie S, Ge D, Urban TJ, Shianna KV, Muir AJ, Fried MW, Afdhal NH, Goldstein DB, McHutchison JG: Variants in the ITPA gene protect against ribavirin-induced hemolytic anemia and decrease the need for ribavirin dose reduction. Gastroenterology 2010, 139:1181-1189.

5. Tanaka Y, Kurosaki M, Nishida N, Sugiyama M, Matsuura K, Sakamoto N, Enomoto N, Yatsuhashi H, Nishiguchi S, Hino K, Hige S, Itoh Y, Tanaka E, Mochida S, Honda M, Hiasa Y, Koike A, Sugauchi F, Kaneko S, Izumi N, Tokunaga K, Mizokami M: Genome-wide association study identified ITPA/ DDRGK1 variants reflecting thrombocytopenia in pegylated interferon and ribavirin therapy for chronic hepatitis C. Hum Mol Genet 2011, 20:3507-3516.

6. Tanaka Y, Nishida N, Sugiyama M, Kurosaki M, Matsuura K, Sakamoto N, Nakagawa M, Korenaga M, Hino K, Hige S, Ito Y, Mita E, Tanaka E, Mochida S, Murawaki Y, Honda M, Sakai A, Hiasa Y, Nishiguchi S, Koike A, Sakaida I, Imamura M, Ito K, Yano K, Masaki N, Sugauchi F, Izumi N, Tokunaga K, Mizokami M: Genome-wide association of IL28B with response to pegylated interferon-alpha and ribavirin therapy for chronic hepatitis $C$. Nat Genet 2009, 41:1105-1109.

7. Hézode C, Forestier N, Dusheiko G, Ferenci P, Pol S, Goeser T, Bronowicki JP, Bourlière M, Gharakhanian S, Bengtsson L, McNair L, George S, Kieffer T, Kwong A, Kauffman RS, Alam J, Pawlotsky JM, Zeuzem S: Telaprevir and peginterferon with or without ribavirin for chronic HCV infection. N Engl $J$ Med 2009, 360:1839-1850.

8. Hoofnagle JH: Thrombocytopenia during interferon alpha therapy. JAMA 1991, 266:849.

9. Yamane A, Nakamura T, Suzuki H, Ito M, Ohnishi Y, Ikeda Y, Miyakawa: Interferon-alpha 2b-induced thrombocytopenia is caused by inhibition of platelet production but not proliferation and endomitosis in human megakaryocytes. Blood 2008, 112:542-550.

10. Li L, Han DK, Lu J: Interferon-a induced severe thrombocytopenia: a case report and review of the literature. World I Gastroenterol 2010, 16:1414-1417.

11. Emilia G, Longo G, Luppi M, Gandini G, Morselli M, Ferrara L, Amarri S, Cagossi K, Torelli G: Helicobacter pylori eradication can induce platelet recovery in idiopathic thrombocytopenic purpura. Blood 2001, 97:812-814

12. Dumoulin FL, Leifeld L, Sauerbruch T, Spengler U: Autoimmunity induced by interferon-alpha therapy for chronic viral hepatitis. Biomed Pharmacother 1999, 53:242-254.

13. Kamal SM, Fehr J, Roesler B, Peters T, Rasenack JW: Peginterferon alone or with ribavirin enhances HCV-specific CD4 T-helper 1 responses in patients with chronic hepatitis C. Gastroenterology 2002, 123:1070-1083.

14. Sagir A, Wettstein M, Heintges T, Haussinger D: Autoimmune thrombocytopenia induced by PEG-IFN-alpha2b plus ribavirin in hepatitis C. Dig Dis Sci 2002, 47:562-563.

15. Johnsen J: Pathogenesis in immune thrombocytopenia: new insights. Hematology Am Soc Hematol Educ Program 2012, 2012:306-312.

16. George JN, Raskob GE, Shah SR, Rizvi MA, Hamilton SA, Osborne S, Vondracek T: Drug-induced thrombocytopenia: a systematic review of published case reports. Ann Intern Med 1998, 129:886-890.

17. Aster RH, Bougie DW: Drug-induced immune thrombocytopenia. N Engl J Med 2007, 357:580-587.

doi:10.1186/1756-0500-7-141

Cite this article as: Jiang et al: Severe thrombocytopenia in a patient with inosine triphosphatase (ITPA)-CC genotype caused by pegylated interferon (IFN)-a-2a with ribavirin therapy: a case report. BMC Research Notes 2014 7:141.

\section{Submit your next manuscript to BioMed Central and take full advantage of:}

- Convenient online submission

- Thorough peer review

- No space constraints or color figure charges

- Immediate publication on acceptance

- Inclusion in PubMed, CAS, Scopus and Google Scholar

- Research which is freely available for redistribution

Submit your manuscript at www.biomedcentral.com/submit
C Biomed Central 